\title{
ATTICUS FINCH: INTELIGENCIA EMOCIONAL Y LIDERAZGO, COMO HERRAMIENTAS DE GESTIÓN, EN EL EJERCICIO DE LA ABOGACÍA. (ANÁLISIS DE LA PELÍCULA «MATAR A UN RUISEÑOR»)
}

\author{
Atticus Finch: Emotional Intelligence and Leadership, as
} Management Tools, in the Exercise of the Legal Profession. (Analysis of the film "To kill a Mockingbird")

\author{
Manuel-Óscar Remeseiro Fernández \\ Doctorando en Derecho y Ciencias Sociales \\ Universidad Nacional de Educación a Distancia (U.N.E.D.)
}

http://dx.doi.org/10.18543/ed-67(2)-2019pp321-351

Recibido: 12.11 .2018

Aceptado: 16.12.2019

\section{Resumen}

A lo largo del presente artículo pretendemos demostrar la importancia que la inteligencia emocional tiene, como herramienta de gestión, en el ejercicio de la abogacía, y que, por las características específicas de la actividad forense, no puede desligarse de otro aspecto esencial del desempeño profesional de los abogados: la capacidad de liderazgo. El jurista ideal debería contar con una buena dosis de ambas cualidades: de la primera; para comprender el funcionamiento de las emociones y las relaciones humanas, y sus implicaciones en los casos en que interviene; de la segunda; para plantear, de forma convincente, las estrategias procesales más pertinentes en cada supuesto y llevarlas a buen puerto. El personaje de Atticus Finch (Gregory Peck), protagonista de la película «Matar a un ruiseñor» (1962), constituye, entendemos, un ejemplo paradigmático, a este respecto y es, por ello, objeto de nuestro análisis.

\section{Palabras clave}

Abogacía, Inteligencia emocional, Liderazgo. 


\begin{abstract}
Throughout this article we intend to demonstrate the importance of emotional intelligence, as a management tool, in the practice of law, and that the specific characteristics of forensic activity, cannot be separated from other essential aspect of professional performance of lawyers: the leadership. The ideal jurist should have a good dose of both attributes: the first; to understand the functioning of emotions and human relationships, and its implications in the cases in which they are involved; the second; to suggest, convincingly, the most relevant procedural strategies in each case. The character of Atticus Finch (Gregory Peck), protagonist of the film «To kill a Mockingbird» (1962), is, as we understand, a paradigmatic example regarding to this, so therefore, a proper case for our paper.
\end{abstract}

\title{
Keywords
}

Advocacy, Emotional intelligence, Leadership. 


\begin{abstract}
Sumario: I. InTRoducción. II. AtTicus Finch Y LA INTELIGENCIA EMOCIONAL COMO HERRAMIENTA DE GESTIÓN PROFESIONAL DEL ABOGADO. III. EL ESTILO DE LIDERAZGO DE ATTICUS FINCH Y SU TRASCENDENCIA EN LA DEFENSA DE TOM ROBINSON. IV. VALORACIÓN CRÍTICA DE LA PELÍCULA. V. CONCLUSIONES. BIBLIOGRAFÍA.
\end{abstract}

\title{
I. INTRODUCCIÓN
}

La inteligencia emocional y la capacidad de liderazgo son dos cualidades indispensables en todo buen jurista. El abogado Atticus Finch (Gregory Peck), en la película «Matar a un ruiseñor» (1962), posee una buena dosis de ambas y, por ello, va a ser objeto de nuestro análisis. El hecho de que se trate de un personaje de ficción no disminuye su elevado valor icónico-simbólico. Por dos razones esenciales: su conducta supone una firme defensa de la legalidad, en un contexto socioeconómico complejo y adverso, y, además, apuesta por resolver la injusticia dentro del sistema, aun dejando entrever sus profundos fallos y contradicciones.

Antes de comenzar a estudiar, más detalladamente, las dos cualidades antes mentadas, y como se ponen de manifiesto, en escenas concretas de la película, es conveniente que fijemos las coordenadas espaciotemporales, que determinan el entorno en el que se desenvuelve la actividad vital, y profesional, del protagonista.

La acción del filme, basado en la novela homónima de la escritora Harper Lee, transcurre en el pueblo imaginario de Maycomb (Alabama), al sur de los Estados Unidos, en el año 1932, durante los años de la «Gran Depresión», posteriores a la crisis bursátil de 1929. Allí, el abogado, viudo y de mediana edad, Atticus Finch vive con sus dos hijos: Jem, de diez años y Scout, de seis (que es la narradora de la historia, ya en la edad adulta). Finch es, lo que podríamos denominar, un "pilar de su comunidad»: profesional reputado y querido por sus vecinos, que acuden a él para solventar sus problemas jurídicos. Ese aserto respecto a sus conciudadanos, y su prestigio como letrado, llevan al juez local, el señor Taylor, a turnarle de oficio un caso conflictivo: el fiscal del distrito acusa a un hombre afroamericano (Tom Robinson) de la violación de una mujer blanca (Mayella Ewell). A través de la mirada inocente, de la pequeña Scout, y de su hermano Jem, somos testigos del devenir de los acontecimientos y de los conflictos que estos desencadenan. Tom Robinson es condenado, por un jurado compuesto enteramente de hombres blancos, sin que existan pruebas concluyentes en su contra, y a pesar del buen hacer de Atticus que demuestra, fehacientemente, durante el juicio, que la víctima, y su padre (testigo principal) cometen perjurio en sus declaraciones. Robinson muere poco después, como consecuencia de un disparo de la policía, cuando intentaba escapar, durante un 
traslado carcelario, presa del pánico y de una profunda desesperación. Robert Ewell, el padre de Mayella, borracho y maltratador, no perdona a Finch el haber defendido a Tom Robinson y trata de hacerles daño a sus hijos. Es entonces cuando otro vecino, Boo Radley (un joven disminuido psíquico al que su familia oculta en casa por vergüenza) salva a Jem y Scout y mata a Ewell. El fuerte sentido ético de Finch le impele a la comunicación de lo ocurrido a las autoridades. Piensa, por un momento, que su hijo Jem ha podido matar a Ewell. No obstante, al haber actuado en legítima defensa sería absuelto fácilmente. El sheriff del condado, el Sr. Tate, le dice que tal cosa resulta inverosímil (parece meridianamente claro que Boo Radley acuchilló a Ewell), y le persuade de la conveniencia de aducir que Ewell se mató al caer sobre su propio cuchillo y cerrar así el caso; puesto que cree que, el destino, en un golpe de justicia poética, ha compensado la muerte de un hombre inocente con la de un hombre culpable. Hacer lo contrario, y dada la animadversión que los vecinos tenían al difunto Ewell, provocaría la conversión del otrora escondido Boo Radley en una figura popular. Lo que acabaría perjudicando a este último y sería, según Scout, como «matar a un ruiseñor» (de ahí, el título de la película).

A modo de conclusión, de este epígrafe introductorio, señalar que casos muy similares, al que narra el guion, ocurrieron en la realidad. Quizás, el más conocido sea el llamado: "Caso de los muchachos de Scottsboro», que tuvo lugar en 1931, y en el que nueve menores afroamericanos fueron acusados, por un grupo de adolescentes blancos, de la presunta violación, en un tren de mercancías, de dos chicas blancas (acción por la que serían condenados, sin pruebas concluyentes, $y$, también, por un jurado compuesto exclusivamente por hombres de esta última raza). Tras varios recursos, el Tribunal Supremo de los Estados Unidos ordenó la repetición del juicio. En esa ocasión, el encargado de la defensa fue el famoso abogado neoyorkino Samuel Leibowitz, miembro del Partido Demócrata, (quien, además, renunció a la percepción de sus honorarios) y que consiguió demostrar, en el acto del juicio, como una de las dos supuestas víctimas había mentido, por miedo a ser acusada del delito de prostitución. A pesar de lo anterior, los procesados fueron declarados culpables y condenados a penas que oscilaban entre los setenta y cinco años de cárcel y la pena de muerte ${ }^{1}$. Finalmente, ninguno de ellos sería ejecutado. Las

${ }^{1}$ Ver, sobre el caso, la página web de la biblioteca de la Facultad de Derecho de la Universidad de Cornell, donde se licenció el abogado Samuel Leibowitz: https://web.archive.org/web/20070719194229/http://library.lawschool.cornell.edu/WhatWeHave/SpecialCollections/Scottsboro.cfm

También, la página web: «Juicios estadounidenses famosos», del Profesor Douglas Linder, de la Facultad de Derecho, de la Universidad de Missouri-Kansas: https://web. archive.org/web/20070710224417/http://www.law.umkc.edu:80/faculty/projects/ftrials/ scottsboro/scottsb.htm 
similitudes entre los dos casos resultan evidentes, si bien parece que Harper Lee, la autora de la novela, en que se basa la película, se inspiró en la figura de su propio padre, también abogado y que, en 1919, defendió a dos afroamericanos en un asunto penal resultando estos condenados, respectivamente, a las penas de ahorcamiento y mutilación. Tras ello, el padre de Lee no volvió a llevar casos penales nunca más (Shields. 2006: 120-121).

\section{ATTICUS FINCH Y LA INTELIGENCIA EMOCIONAL COMO HERRAMIENTA DE GESTIÓN PROFESIONAL DEL ABOGADO}

El concepto de «inteligencia emocional» surge, en los años 80, cuando algunos psicólogos se dan cuenta de que la definición tradicional de «inteligencia», excesivamente ligada al concepto de «cociente intelectual» (C.I.) del individuo, no ponderaba otra serie de aspectos que pueden resultar infinitamente más relevantes en nuestras vidas que aquellos que, rígidamente, evaluaban, los cuestionarios al uso. El cambio de paradigma se produciría, en buena medida, tras las aportaciones teóricas de Howard Gardner.

Howard Gardner, psicólogo, y profesor de la Facultad de Ciencias de la Educación de la Universidad de Harvard, publicó en el año 1983 su libro: «Frames of Mind: The Theory of Multiple Intelligences». En él, desarrolla la «Teoría de las inteligencias múltiples» y subdivide la inteligencia en siete inteligencias diferentes: lingüística, lógico-matemática, musical, espacial, capacidad de coordinación del movimiento corporal, interpersonal e intrapersonal. (Gardner. 1983: 9) La inteligencia emocional, para Gardner, estaría vinculada a las dos últimas: tanto a la inteligencia interpersonal (dotes de liderazgo, aptitud para establecer y mantener relaciones personales, capacidad de solucionar conflictos y habilidad para el análisis social); como a la inteligencia intrapersonal (autoconocimiento, motivación y capacidad de introspección).

David Goleman, influyente psicólogo y exprofesor de la Universidad de Harvard, valora, de este modo, algunas de las implicaciones de la teoría de Gardner:

«Si hay una persona que comprende las limitaciones inherentes al antiguo modo de concebir la inteligencia, ésa es Gardner, que no deja de insistir en que los días de gloria del C.I. han llegado a su fin. El creador del test de papel y lápiz para la determinación del C.I. fue un psicólogo de Stanford, llamado Lewis Terman, durante la Primera Guerra Mundial, cuando dos millones de norteamericanos fueron clasificados mediante la primera aplicación masiva de ese test. Esto condujo a varias décadas de lo que Gardner denomina «el pensamiento C.I.», un tipo de pensamiento según el cual «la gente es inteligente o no lo es, la inteligencia es un dato innato (y no hay mucho que podamos hacer, a este respecto, para cambiar las cosas) y exis- 
ten pruebas para discriminar entre ambos grupos. El test S.A.T. que se realiza para entrar en la universidad se basa en el mismo principio de que una prueba de aptitud sirve para determinar el futuro. Esa forma de pensar impregna a toda nuestra sociedad» (Goleman. 1996: 73-74).

Pero ¿qué es y en qué consiste, en realidad, la inteligencia emocional?:

«La inteligencia emocional es aquella parte de la inteligencia social que se refiere a la capacidad de percibir los sentimientos y emociones, propios y ajenos, para, meditando sobre ellos, utilizar esa información para guiar las propias acciones y pensamientos» (Salovey y Mayer. 1990: 189). Esta definición tiene un carácter holístico e incluye, dentro de la «inteligencia social», a las inteligencias personal e intrapersonal de Gardner. Salovey y Mayer, subsumieron los siete tipos de inteligencias, de éste, y las agruparon, en cinco áreas de competencias principales (Goleman. 1993: 83-85):

«1. Conocimiento de las propias emociones. 2. Capacidad de controlar las emociones. 3. La capacidad de motivarse uno mismo. 4. El reconocimiento de las emociones ajenas. 5. El control de las relaciones»».

Serán estos, los cinco parámetros que utilizaremos para analizar la inteligencia emocional de Atticus Finch. Lo haremos mediante la descripción detallada de escenas concretas de la película, y el estudio de su aplicabilidad práctica al ejercicio cotidiano de la abogacía.

\section{Conocimiento de las propias emociones (Autoconocimiento)}

Entendemos como tal, la capacidad de reconocer un sentimiento propio, en el mismo momento en que aparece. Constituye la piedra angular de la inteligencia emocional (Goleman. 1993: 83). Dicha capacidad es indispensable para la introvisión psicológica y para la comprensión de uno mismo e incluye, también, la intuición. Veamos un par de ejemplos del ejercicio práctico del autoconocimiento por parte de Atticus Finch:

\subsection{Análisis de la escena en que el Juez Taylor visita a Atticus y le} comunica que está pensando encargarle, de oficio, la defensa de Tom Robinson

(Es de noche, Finch está sentado en el porche de su casa, meditando, tras haber acostado a sus hijos, y el Juez Taylor llega de visita):

JUEZ TAYLOR. Buenas noches, Atticus.

ATTICUS. Buenas, Señor Juez. ¿Hace calor verdad?

JUEZ TAYLOR. (Acerca una silla y se sienta junto a Atticus). Sí, ya lo creo. ATTICUS. ¿Cómo está su esposa?

JUEZ TAYLOR. Mucho mejor. Gracias. (Cambiando de tema) ¿Te has enterado de lo de Tom Robinson? 
ATTICUS. Sí señor.

JUEZ TAYLOR. Mañana se le formularán los cargos ante el jurado. Yo... estaba pensando en nombrarte defensor de oficio, aunque sé que estás muy ocupado con los asuntos de tu bufete y que tus chicos te llevan gran parte de tu tiempo.

ATTICUS. Cierto. (Medita un momento, antes de responder). Aceptaré el caso. $^{2}$

Podría sorprendernos la celeridad con la que Atticus acepta la propuesta del juez Taylor, pero en eso consiste la aplicabilidad del autoconocimiento a la toma de decisiones: analizar la información disponible, a veces en poco tiempo, y dejarse guiar, en buena medida, por la intuición. En palabras de Goleman, Boyatzis y McKee:

«La intuición es una habilidad que se deriva de la conciencia de uno mismo y que permite al líder recurrir no sólo a sus conocimientos técnicos, sino aplicar también su sabiduría de la vida. (...) No debemos olvidar que la investigación neurológica ha puesto de manifiesto que la memoria emocional nos capacita para juzgar adecuadamente la información (...) En resumen, la intuición brinda a los líderes emocionalmente inteligentes una puerta de acceso a la sabiduría vital acumulada sobre un determinado tema. Pero, para poder escuchar ese mensaje, es necesario conocerse a uno mismo.» (Goleman, Boyatzis y McKee. 2002: 75-78).

\subsection{Análisis de la escena en la que Atticus explica a Scout por qué defiende a Tom Robinson}

El autoconocimiento de uno mismo implica, además de la intuición, estudiada en la escena anterior, el seguimiento de las propias convicciones. En este diálogo, Finch expone a su hija, de forma sumamente didáctica, el alcance de sus principios y lo hace reconociendo la madurez de ésta, a pesar de su corta edad:

(Por la tarde, Scout está sentada en las escaleras del porche, con la cabeza sobre las rodillas. Parece abatida. Atticus acaba de llegar y se dirige hacia ella):

ATTICUS. (Preocupado) Pero... Scout ¿Qué te pasa?

SCOUT. Atticus, ¿Tú defiendes a esos despreciables negros?

ATTICUS. (Contrariado) ¡No hables así de ellos!

SCOUT. (Explicándose) No soy yo, sino Cecil Jacobs, y me peleé con él por eso.

ATTICUS. (Disgustado) Scout, no quiero que te pelees con nadie.

SCOUT. Tuve que hacerlo porque...

${ }^{2}$ Robert Mulligan, 1962: 0:16:54. 
ATTICUS. (Le interrumpe) ¡No me importan los motivos! ¡Te prohíbo que vuelvas a pelearte!

SCOUT. Está bien.

ATTICUS. De todos modos, me encargo de la defensa de un negro: Tom Robinson. Scout, aún eres demasiado pequeña para llegar a comprender ciertas cosas. La verdad es que se ha hablado mucho en esta población respecto al hecho de que no debería defender a ese hombre.

SCOUT. Si no deberías defenderle, entonces, ¿por qué lo haces?

ATTICUS. Entre varias razones, porque si no lo hiciera no podría ir con la cabeza bien alta. Ni siquiera podría deciros a ti y a Jem qué es lo que debéis hacer. Scout, oirás en la escuela muchas murmuraciones sobre este asunto, pero quiero que me prometas una cosa: que no volverás a pelearte a causa de ello, a pesar de que digan lo que digan.

SCOUT. Te lo prometo. ${ }^{3}$

Tras la conversación padre-hija, a Scout le queda muy clara la razón de porqué su padre defiende a un afroamericano: lo hace por una cuestión de integridad personal y, también, profesional: todo ser humano tiene derecho a una adecuada defensa letrada y esa premisa es, para Atticus, algo innegociable, más allá de los infundios, y vilezas, que alguna gente pueda sembrar contra su buen nombre. Y, más allá, también, de la raza y la extracción social de cada uno. En este sentido, suscribimos la acerada observación de la criminóloga Nicole Rafter:

«Matar a un ruiseñor, (1962), rodada en pleno auge del «movimiento por los derechos civiles», ataca directamente a una América que lucha por reconciliar su diversidad y diferencias. (El año anterior, John Ford filmaba «El sargento negro», una película del oeste en la que un oficial de caballería afroamericano era acusado, falsamente, de robar y violar a una mujer blanca). El jurado permanece ciego a todos los detalles del caso, excepto a que el acusado es un hombre afroamericano y la víctima una mujer blanca. La mendaz acusación de violación, de esta última, es tomada en consideración por la ciudad, el jurado y el sistema jurídico penal, pero el solo hecho de que Atticus Finch (Gregory Peck), el heroico abogado defensor, haya llevado el caso es un símbolo de que el sistema puede ser redimido» (Rafter. 2006: 40).

De ahí, la importancia de los valores individuales, las propias convicciones y del autoconocimiento de estos, en el ejercicio responsable de la abogacía. En un alarde de inteligencia emocional aplicada, el abogado Atticus Finch nos demuestra que no puede, ni debe, ver condicionada su actuación en un proceso por el temor al rechazo de la comunidad o por miedo a las opiniones que puedan verterse en su contra. Esto último, nos llevaría a que, en aquellos casos más polémicos (como el del propio Tom Robinson), o de

\footnotetext{
3 Robert Mulligan, 1962: 0:51:13.
} 
perfil mediático más acusado, la calidad de la defensa del justiciable podría verse comprometida por presiones externas, y ajenas, al propio sistema jurídico penal. Este tipo de presiones, pueden llegar a conformarse, en la práctica, como una sutil herramienta de control social informal y/o una suerte de mecanismo de linchamiento colectivo.

Por eso mismo, ya en textos de la época de la Ilustración se conminaba a los abogados a extremar las cuestiones éticas, y a no olvidar la defensa del desfavorecido, en la actividad forense. Veamos un ejemplo, de 1794, del libro «Ciencia del foro o Reglas para formar un abogado»:

«Regla X. Es de la mayor consecuencia para el buen crédito de un Abogado, que los motivos que lo animan a la defensa de las causas, sean siempre los más puros y conformes a la verdad. Por lo mismo, nunca debe dar la menor ocasión de pensar que hay por su parte alguna mira de interés, odio, venganza, o cosa semejante. En esto consiste la buena opinión de su conducta. (...)

Regla XVI. Debe el Abogado defender la causa de la viuda, del huérfano y del pobre, con la misma eficacia, actividad, e interés, que las de las personas más ricas y poderosas.» (Varios autores. 1794: 143-149).

\subsection{Análisis de la escena en la que Atticus y el sheriff Tate dirimen la conveniencia, o no, de comunicar las circunstancias del fallecimiento de Bob Ewell a las autoridades}

(Es de noche, Atticus y el sheriff, Heck Tate, han salido a conversar al porche):

ATTICUS. (Preocupado) Heck, yo creo que... Sí, creo que lo que hay que hacer es... (Scout sale al porche con Boo Radley y ambos se sientan en el columpio que hay al fondo de él) ¡Dios mío!, estoy perdiendo la memoria... No puedo recordar que edad tiene Jem, si son doce o trece años (diez, en el guion original de la película).

De todos modos, habrá que llevar esto ante los tribunales del condado... Claro que es un caso evidente de legítima defensa. Yo, en fin... Tendré que presentar el caso.

TATE. (Convincente y, a la vez, en tono muy serio) Señor Finch, ¿usted cree que Jem mató a Ewell?, ¿es lo que piensa? Su hijo no lo apuñaló. (Ambos miran a Boo Radley) Bob Ewell cayó sobre su cuchillo. Él se mató. Un negro murió, sin culpa alguna, y, ahora, ha muerto el culpable de su muerte. Deje que, esta vez, un muerto entierre a otro muerto, señor Finch. Nunca he oído decir que sea contrario a la ley que un ciudadano haga todo lo posible para evitar un crimen. Que es, exactamente, lo que él ha hecho (se refiere a Boo Radley). Quizá, usted me diga que mi obligación es declarar la verdad y no ocultársela al pueblo. Pero ¿sabe qué pasaría? Que todas las señoras de Maycomb, incluyendo a mi mujer, irían a llamar a su puerta para regalarle dulces y pasteles. A mi modo de pensar, coger a un hombre que ha hecho un gran favor, a usted y a la población, y 
tratar de sacarlo, con su dulce timidez, a la luz pública, es un pecado...Sí, señor. Lo es. Y, por mi parte, no he de cometerlo. No soy hombre importante, señor Finch, pero todavía soy el sheriff del condado. (Tajante) Bob Ewell se cayó sobre su cuchillo. Buenas noches. (Tate se va).

SCOUT. (Se acerca a su padre, quien la pone de pie sobre una silla, y le acaricia los brazos) El señor Tate tiene razón...

ATTICUS. ¿Qué quieres decir?

SCOUT. Que eso sería algo así como matar a un ruiseñor, ¿no crees? (Atticus abraza a Scout $)^{4}$

Esta escena de la película nos plantea un dilema ético esencial, que afecta tanto al protagonista como al sheriff Tate, quien representa, en última instancia, a la autoridad: ¿Debe llevarse la aplicación de la ley hasta sus últimas consecuencias o ha de ponderarse buscando la conciliación de ésta con el bien común? No es una pregunta nueva, en el mundo jurídico, y ya Cicerón, en el año 44 antes de Cristo, nos ilustraba sobre el particular:

«Porque es necesario referirse, en todo, a aquellos fundamentos de la justicia que propuse al principio; lo primero, que no se haga daño a nadie, y lo segundo, que se mire por la común utilidad (...) Provienen, también, algunas injusticias de las cavilaciones y de la astuta, y maliciosa, interpretación de las leyes. De modo que se usa ya, como proverbio vulgar, aquel dicho: «El sumo rigor del derecho viene a ser suma injusticia» («Summun ius, summa iniuria»)». (Peñalosa. 1998: 12).

Esta modulación de los efectos adversos de la aplicación, puramente

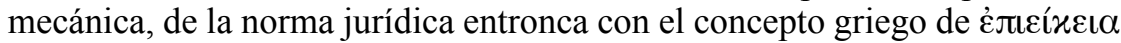
(epiqueya). Santo Tomás de Aquino, influido por Aristóteles, la define así:

«Como vimos anteriormente, al tratar de las leyes, por ser los actos humanos, sobre los que recaen las leyes, singulares y contingentes, que pueden ofrecer ilimitadas formas, no fue posible establecer una ley que no fallase en un caso concreto. Los legisladores legislan según lo que sucede en la mayoría de los casos, pero observar punto por punto la ley en todos los casos va contra la equidad y el bien común, que es lo que persigue la ley. Así, por ejemplo, la ley ordena que se devuelvan los depósitos, porque esto es normalmente lo justo; pero puede a veces ser nocivo: pensemos en un loco que depositó su espada y la reclama en estado de demencia, o si uno exige lo que depositó para atacar a la patria. Por tanto, en estas y similares circunstancias sería peligroso cumplir la ley a rajatabla; lo bueno es, dejando a un lado la letra de la ley, seguir lo que pide la justicia y el bien común. Y a esto se ordena la epiqueya, que entre nosotros se llama «equidad»: Por tanto, es evidente que la epiqueya es virtud.» (Aquino. 2014: 293).

${ }^{4}$ Robert Mulligan, 1962: 2:01:06.

5 Tomás de Aquino, 2014: 293. https://www.dominicos.org/media/uploads/recursos/ libros/suma/4.pdf ${ }^{\mathrm{C}}$ onsultada el 23/10/2018). 
Así pues, y, en síntesis, la epiqueya consiste en la interpretación y aplicación de la ley, a cada caso concreto, teniendo en cuenta las circunstancias que en él concurren, y tomando como fiel de la balanza el bien común. Pero ¿cuándo debemos aplicarla?:

Según Francisco Suárez, eximio jurista y teólogo jesuita del siglo XVI, la epiqueya puede aplicarse en tres casos: «a) Para evitar algo injusto: En este caso, se acude a la epiqueya cuando hay otro precepto (de la ley divina o de la natural), al cual sea contraria la ley humana. b) Para evitar la aplicación de una ley excesivamente gravosa: Se analiza la norma tomando en cuenta su obligatoriedad y las circunstancias del caso. Se juzga si por tales circunstancias se escapa a tal obligatoriedad. c) Para dejar de lado la norma analizando la intención del legislador: aquí la epiqueya se aplica tomando en cuenta las circunstancias, la práctica, el tipo de autoridad y soluciones en casos semejantes. Cuando consta con certeza que la materia de la ley, por cualquier circunstancia, se ha convertido en injusta o contraria a otro precepto o virtud más obligatoria, cesa la obligación de la ley y puede prescindirse de la misma por la propia autoridad, sin acudir al superior» ${ }^{6}$.(Pérez. 2017: 274-275).

Una vez definido el concepto de epiqueya, y su margen y criterios de aplicabilidad, parece sensato inferir que el proceder del sheriff Heck Tate y, consiguientemente, el de Atticus Finch son ajustados al espíritu de la ley (y, más concretamente, al tercer supuesto de aplicación de la epiqueya señalado por Suárez). Ambos, emplean su inteligencia emocional para percibir la grave injusticia que cometerían dando parte, sin más, a las autoridades, de lo ocurrido, causando un eventual daño a quien, lejos de provocar mal alguno, ha salvado dos vidas. Esta capacidad de percepción de la injusticia, que debería ser inherente a todo profesional del derecho, se sustenta, en última instancia, en sus convicciones más íntimas. Por eso, el autoconocimiento de uno mismo es una de las piedras angulares de la inteligencia emocional y del bienestar personal. (Goleman. 1993: 91).

\section{Capacidad de controlar las propias emociones (Autocontrol)}

«La conciencia de uno mismo es una habilidad básica que nos permite controlar nuestros sentimientos y adecuarlos al momento. (...) Las personas que carecen de esta habilidad tienen que batallar constantemente con las tensiones desagradables mientras que, por el contrario, quienes destacan en el ejercicio de esta capacidad se recuperan mucho más rápidamente de los reveses y contratiempos de la vida (Goleman. 1993: 83-84). Esta

${ }^{6}$ Matilde Pérez, 2017: 274-275. http://bibliotecadigital.uca.edu.ar/repositorio/revistas/epiqueya-vision-francisco-suarez.pdf (Consultado el 22/10/2018) 
capacidad incluye, para el autor, entre otras habilidades: la gestión del enfado, de la ansiedad y el control de la tristeza. Nos queda claro, tras la lectura de la definición de Goleman, que el primer componente de la inteligencia emocional, el autoconocimiento de sí mismo, está fuertemente vinculado al segundo: la autogestión de las propias emociones, que es el que estudiaremos a continuación. Y ello, por un motivo muy evidente: difícilmente puede gestionar sus emociones aquél que es incapaz de percibirlas. Ese no es el caso de Atticus Finch. En las siguientes líneas, analizaremos tres escenas en las que nuestro personaje hace gala de una envidiable capacidad de control de la ansiedad (en la primera) y del enfado (en la segunda y tercera):

2.1. Análisis de la escena en que Atticus sacrifica un perro rabioso que ponía en peligro al vecindario

(Calpurnia, asistenta afroamericana de los Finch, avisa a Atticus de la presencia de un perro rabioso en las inmediaciones de su casa. Atticus acude enseguida, acompañado por el sheriff Tate que le acerca en su coche. Ambos se bajan del vehículo y observan la situación):

ATTICUS. Ahí está.

TATE. Efectivamente, parece rabioso.

ATTICUS. (Dirigiéndose a Jem) ¡No salgas, hijo, meteos en casa! Está a nuestro alcance, Heck.

TATE. Dispare usted, ¿quiere?

SCOUT. (Preocupada por su padre) Oh no, Sr. Tate. Él no sabe.

ATTICUS. (Animando a Tate a disparar) No pierda tiempo.

TATE. Pero, Señor Finch, hay que matarlo instantáneamente. Antes de que empiece a correr. ¡Mire dónde está! Yo no soy buen tirador.

ATTICUS. (Escéptico) Hace años que no manejo un rifle.

TATE. (Suplicante) Pues, por favor, hágalo usted ahora. (Entrega el arma a Finch).

(Atticus toma el rifle del sheriff Tate y apunta al perro. Sus gafas le molestan, para apuntar, y las deja caer, con suavidad, al suelo. Encañona de nuevo al animal y dispara. Lo alcanza a la primera, con gran sorpresa y estupefacción de sus hijos, especialmente de Jem, quien tenía a su padre por un completo inútil en aquellas actividades cotidianas ajenas a su profesión).

ATTICUS. (A sus hijos) No os acerquéis a ese perro. Es tan peligroso ahora como cuando estaba vivo.

JEM. (Muy sorprendido, todavía) Está bien. Atticus...

ATTICUS. ¿Qué, hijo?

JEM. Nada...

TATE. (Divertido, a Jem) ¿Qué te pasa muchacho? ¿No puedes hablar? ¿No sabías que tu padre es el mejor tirador del contorno? 
ATTICUS. (Modesto) Calle, Heck, ¡volvamos al juzgado! Y recordad que no debéis acercaros a ese perro. (Se sube al coche del sheriff).

JEM. (Todavía muy sorprendido) Descuida.

TATE. Daré aviso para que vengan a retirarlo. ${ }^{7}$

En esta escena, somos testigos de un episodio muy interesante de autogestión emocional. En pocos segundos, Atticus Finch, debe tomar una decisión en un contexto de peligro potencial para su familia y para sí mismo: disparar o no al perro rabioso que se encuentra en las inmediaciones de su casa. Él ha sido buen tirador en su juventud, pero lleva muchos años sin ejercitarse y eso le hace dudar. Pero la duda no le paraliza, porque, en el fondo de su corazón, sabe muy bien lo que es capaz de hacer. De ahí, la importancia del autocontrol para conocer los propios límites en momentos clave. Un aspecto que también tiene importantes aplicaciones en la vida profesional del abogado, como veremos en las siguientes escenas.

\subsection{Análisis del «encontronazo» con Bob Ewell en el juzgado}

(Acabada la vista previa, de la causa de Tom Robinson, en el juzgado de Maycomb, Scout, Tití y Jem son sorprendidos por Atticus, delante de la puerta de la sala de audiencias. Éste, enfadado, les manda volver a casa.):

ATTICUS. (Irritado) Scout. Jem. ¿Se puede saber qué hacéis aquí?

JEM. (Compungido) Hola, Atticus...

ATTICUS. Bueno, hablad. ¿A qué habéis venido?

SCOUT. A ver el sótano en el que encerraron a Boo Radley. Nos dijeron que había murciélagos.

ATTICUS. (Disgustado) Volved a casa inmediatamente, ¿entendido?

JEM. Sí, Atticus.

ATTICUS. Vamos, ¡ligeros! Os veré a la hora de cenar.

(Poco después de que los niños salgan de escena, el señor. Ewell se acerca a Atticus).

EWELL. (Cortándole el paso a Atticus, apoyando su brazo derecho en la pared) Quería verle, señor. Finch.

ATTICUS. Señor Ewell...

EWELL. (En actitud chulesca) Con franqueza, lamento que le hayan confiado la defensa de ese negro que violó a mi hija Mayella. No sé por qué no le maté, en lugar de acudir al sheriff. Les hubiera ahorrado a ustedes, y a los contribuyentes, muchas molestias.

ATTICUS. (Zafándose y haciendo ademán de irse) Discúlpeme, tengo mucha prisa.

EWELL. (Se interpone, de nuevo) Aguarde un momento, por favor. Ahora, mientras salíamos, me han dicho que daba usted crédito a lo que cuenta

\footnotetext{
${ }^{7}$ Robert Mulligan, 1962: 0:42:08.
} 
Tom Robinson en contra de nuestra denuncia. Y yo les he contestado: (se echa a reír, nervioso) eso es un disparate, ¡cómo va el señor Finch a creer más a un negro que a nosotros! (Atticus le observa, impasible). Son habladurías, ¿verdad?

ATTICUS. (Contundente) He sido nombrado para defender a Tom Robinson y es lo que haré, ahora que se han formulado los cargos.

EWELL. (Alterado) ¿Con qué va a ocuparse de...?

ATTICUS. Discúlpeme, señor Ewell. (Se marcha).

EWELL. (De malos modos y gritando, amenazador, mientras Finch se va) ¿Qué clase de hombre es usted? ¡Recuerde que tiene hijos también! ${ }^{8}$

En este diálogo observamos un tipo de conducta que, por desgracia, resulta sumamente habitual tanto en la vida cotidiana como en la profesional: una persona (Bob Ewell) que, ante una forma de actuar determinada, y perfectamente legítima, de otra (Atticus Finch) opta por el enfrentamiento, el chantaje emocional y la descalificación de su semejante. Esa reacción no es casual y esconde un poderoso detonante: el miedo. El miedo a que un abogado competente como Finch descubra que la denuncia de Ewell es completamente falsa y que el acusado, Tom Robinson, es inocente. La forma de obrar de Bob Ewell es intrínsecamente «malvada», sabe cómo han ocurrido los hechos realmente pero no le importa, en absoluto, comprometer la vida, o la integridad, de una persona inocente y tampoco amenazar a quien, honesta y profesionalmente, opta por defenderlo. Para auto-justificarse, recurre a un mecanismo mental: la negación optimista (Goleman. 1993: 137). La cadena de pensamientos en la mente de Bob Ewell sería algo así como: «De acuerdo, él no lo hizo, pero es un maldito negro y estaba con mi hija Mayella, así aprenderá a dejar en paz a las mujeres blancas». La utilidad de dicho esquema mental de razonamiento es que, quien así procede, no sienta ningún tipo de remordimiento por su conducta. El perfil psicológico de Bob Ewell no es, desde luego, un modelo de equilibrio emocional: alcohólico, maltratador, de extracción social humilde, viudo a cargo de una familia numerosa, de muy bajo nivel cultural y con graves problemas económicos (los granjeros sufrieron con especial dureza la crisis provocada por la crisis bursátil de 1929 y recordemos que la acción de la película transcurre en 1932). El personaje se halla, por tanto, fuertemente condicionado por sus circunstancias. En el lado contrario, Atticus Finch reacciona de forma comedida pero contundente ante la actitud desafiante de Ewell. Finch, no pierde el control en ningún momento $y$, elegantemente, trata de evitar el enfrentamiento, pero, cuando este se produce, expresa de forma asertiva su forma de pensar, dejando claro a Ewell que no se siente intimidado por éste. No se deja provocar y no entra en su espiral de violencia. ¡Qué mejor ejemplo de una elevada capacidad de gestión de las propias emociones!

\footnotetext{
8 Robert Mulligan, 1964: 0:22:40.
} 
2.3. Análisis del enfrentamiento con Ewell frente a la casa de Tom Robinson

(Atticus debe acudir a casa de Tom Robinson, a comunicar a su familia que ha fallecido, tratando de escapar, cuando era conducido a la cárcel de Abbotsville. Jem se empeña en acompañar a Atticus y se queda en el coche mientras su padre entra a hablar con Helen, la mujer de Tom. Delante del porche están reunidos familiares y amigos de Tom.)

SPENCE. ¿Cómo está, señor Finch? Soy Spence, el padre de Tom. ATTICUS. ¡Qué tal, Spence! (Hace una pausa larga, como para tomar aliento) ¿Está Helen?

SPENCE. Sí señor. Se ha echado para intentar dormir un rato. Estábamos hablando de la apelación, señor Finch. ¿Cuánto tiempo cree usted que tardará?

ATTICUS. Spence, no hace falta ya ninguna apelación. Ya no. Tom ha muerto.

SPENCE. (Impresionado) Muerto...

ATTICUS. (La mujer de Tom aparece en el porche) Helen... (Ella ve a Atticus, intuye la noticia, y se desmaya).

(Jem sigue los acontecimientos, muy impresionado, desde dentro del coche. Aparece Ewell y se queda, observando todo lo que ocurre, junto al vehículo de Finch. Los familiares de Tom entran en la casa y fuera permanecen algunos hombres, amigos o vecinos).

EWELL. (Borracho, y en tono de chulería, se dirige a uno de los afroamericanos allí congregados) ¡Eh, tú! Entra a decirle a Atticus Finch que he dicho yo que salga aquí. Anda, entra...

(El hombre entra en la casa. Poco después, Atticus sale y se dirige hacia Ewell. Cuando está a su altura le mira fijamente. De repente, Ewell le escupe a la cara. Atticus sostiene la mirada, respira hondo y se limpia el escupitajo con un pañuelo, que tira al suelo. Acto seguido, ignora a Ewell, sube al coche y se marcha con Jem. Las luces del vehículo iluminan el rostro de Bob Ewell, que refleja un odio sin límites. ${ }^{9}$

Esta escena podría definirse como una versión «agravada» de la que hemos analizado en el sub-epígrafe anterior. Por dos motivos principales: Tom Robinson ha muerto, al intentar escapar durante un traslado carcelario, y Bob Ewell, dejado en evidencia en el juicio por Finch, canaliza todo su odio hacia éste, mostrándonos su carácter vengativo. Lo primero que llama la atención de la conducta de Ewell es su desfachatez. Es capaz de presentarse en la casa de Tom Robinson, que ha muerto por su culpa, para desafiar a Finch. Este tipo de comportamiento, carente de un ápice de empatía, lo sitúa en el ámbito de la delincuencia psicopática. (Goleman. 1993: 186-189).

${ }^{9}$ Robert Mulligan, 1964: 1:46:36. 
Ewell, escupe, groseramente, en la cara, a Finch quien, de nuevo, no cae en la provocación y arroja al suelo el pañuelo, con el que se limpia el escupitajo, en señal de contenido, pero contundente, desprecio hacia su agresor; al que ignora, mientras accede a su vehículo, para marcharse, con su hijo Jem, a casa. En ese momento, vemos el odio reflejado en la mirada de Ewell. Un odio cerval que anuncia una inminente venganza.

\section{La capacidad de motivarse uno mismo (Automotivación)}

Otro elemento nuclear de la inteligencia emocional lo constituye la capacidad del individuo de motivarse a sí mismo. Esta habilidad permite la superación de los obstáculos y experiencias negativas mediante el incremento de la confianza en las propias cualidades. Además, los individuos con una actitud positiva ante la vida, en general, construyen experiencias interpersonales que les facilitan la consecución de mejores resultados en sus quehaceres y la obtención de grandes satisfacciones para sí mismos y para quienes les rodean (Salovey y Mayer. 1990: 200).

En el siguiente fragmento, Atticus finaliza su intervención en la sala de vistas y exhorta a los miembros del jurado a cumplir, con lealtad, sus obligaciones como ciudadanos. Se muestra confiado, pero no iluso. Y es una distinción importante, porque no debemos confundir el optimismo con la ingenuidad.

(Atticus está en la sala de vistas concluyendo su alegato final ante el jurado y quiere trasladar, a los miembros de éste, la importancia de que cumplan con su deber en el ejercicio de la función jurisdiccional).

ATTICUS. (Solemne) Bien, señores. En este país los tribunales tienen que ser de una gran equidad. Y, para ellos, todos los individuos han nacido iguales. No soy un iluso que crea, firmemente, en la integridad de nuestros tribunales y en el sistema del jurado. No me parece lo ideal, pero es una realidad a la que no hay más remedio que sujetarse. Pero ahora, confío en que ustedes, señores, examinarán, sin prejuicios de ninguna clase, los testimonios que han escuchado y su decisión devolverá a este hombre al seno de su familia. (Hace una pausa larga) En el nombre de Dios, cumplan con su deber. En el nombre de Dios, den crédito a Tom Robinson. ${ }^{10}$

(Cuando el jurado concluye sus deliberaciones, la sesión vuelve a reanudarse):

AGENTE JUDICIAL. Se reanuda la sesión. Levántense. (El juez Taylor entra en la sala y todos los asistentes se ponen en pie. Cuando el juez toma asiento el resto hacen lo propio).

JUEZ TAYLOR. (Mirando hacia el jurado) Señores del jurado, ¿han acordado, ustedes, su veredicto?

${ }^{10}$ Robert Mulligan, 1962: 1:34:35. 
PORTAVOZ. Sí, señor juez.

JUEZ TAYLOR. El acusado debe ponerse de pie de cara al jurado. (Tom se levanta y mira al jurado).

¿Cuál es el veredicto?

PORTAVOZ. Hallamos culpable al acusado de los hechos que se le imputan (Tom Robinson se sienta. Su rostro denota desolación. Se hace un gran silencio en la sala).

JUEZ TAYLOR. Señores, el jurado puede retirarse.

AGENTE JUDICIAL. La vista ha terminado. (El juez Taylor se levanta y abandona la sala. El resto de los asistentes también comienzan a abandonar el local).

ATTICUS. (Dirigiéndose a Tom Robinson, en tono calmado e intentando tranquilizarle, mientras es conducido a la cárcel por varios agentes) Iré a ver a Helen mañana. Ya le dije a usted que no se apurase, aunque perdiésemos el juicio en primera instancia... Tom... (Robinson le mira, desconsolado, sin poder articular palabra) ${ }^{11}$

En este caso, el optimismo no ha servido a Finch para superar el primer envite judicial, pero, lejos de desmoronarse, se dispone a encarar la segunda instancia con plena convicción en sus posibilidades de triunfo y así se lo hace saber a su cliente, quien, visible y comprensiblemente, desolado por el veredicto, no es capaz de asimilar lo que le dice su letrado. El optimismo, como componente básico de la motivación, no garantiza, per se, el éxito, pero puede convertirse en una potente herramienta para reformular el fracaso. A su vez, el enfoque optimista de un problema incrementa, exponencialmente, las posibilidades de solucionarlo. Como dijo el general estadounidense Colin L. Powell, en su Decálogo: «el optimismo perpetuo es un multiplicador de fuerza $»^{12}$ (Powell. 2012: 3-4).

\section{El reconocimiento de las emociones ajenas (Empatía)}

Para Salovey y Mayer, la empatía es: «La peculiar, e interesante, interacción entre la valoración emocional y la expresión de los sentimientos: la capacidad de comprender los sentimientos de los otros y volver a experimentarlos uno mismo. Rogers creía que el esfuerzo activo para comprender a otros, y empatizar con ellos, es un valioso regalo y una premisa esencial para ayudarles a crecer como personas. La empatía se configura como una característica clave de la inteligencia emocional. Tal y como los científicos sociales han demostrado, en los últimos años, los familiares, amigos y vecinos de una persona constituyen una crucial aportación a su bienestar. Cuando

\footnotetext{
${ }^{11}$ Robert Mulligan, 1962: 1:37:40

12 Colin L. Powell, 2012: 3-4.
} 
alguien se relaciona con otro, de forma positiva, éste experimenta una gran satisfacción vital y un menor grado de estrés. Por ejemplo, la empatía de un asesor es un elemento decisivo para que este sea percibido como competente. La empatía es, además, un elemento favorecedor del comportamiento altruista. Las personas con alto grado de empatía acostumbran a desarrollar la competencia social necesaria para establecer un extenso entramado de relaciones interpersonales». (Salovey y Mayer. 1990: 194).

No se nos ocurre mejor ejemplo práctico, para ilustrar la definición de empatía de Salovey y Mayer, que la escena en la que Atticus Finch conversa durante unos minutos con su anciana vecina, la señora Dubose. Haciendo muestra de una excepcional capacidad empática, consigue mitigar los sentimientos negativos de una mujer, enferma crónica, cuyo mal carácter no es sino un síntoma de la elevada frustración que le acarrean tanto sus dolencias como su soledad:

\subsection{Analisis de la escena en que Atticus conversa con la señora Dubose}

(La Sra. Dubose, está sentada, en el porche de su casa, y Atticus la saluda, muy amablemente. Le acompañan Jem, Scout y Tití):

ATTICUS. Buenas tardes, Sra. Dubose. Pero, caramba... (Zalamero) ¡Qué buen aspecto tiene usted hoy!

SCOUT. (Irónica, susurrando a Jem y Tití) No dice qué clase de aspecto. ATTICUS. ¡Y qué flores tan bonitas las de su jardín! Nunca he visto nada tan maravilloso. Señora Dubose, le aseguro que las de los jardines de Bellingrath no tienen comparación con las suyas.

SRA. DUBOSE. (Halagada) Más lozanas eran las de años anteriores...

ATTICUS. (Convincente) Siento no estar de acuerdo con usted. Creo que su jardín es la envidia de toda la población.

JEM. (Susurrando a Tití, detrás de Atticus) Le habla de sus chifladuras para que no sea tan gruñona.

ATTICUS. Bueno, encantado de saludarla, Sra. Dubose.

(Atticus, Jem, Scout y Tití se marchan y continúan caminando por la calle) ${ }^{13}$

Atticus regresa de su despacho, concluidas sus tareas profesionales, y debe pasar por delante de la casa de su vecina. Conocedor de las circunstancias de ésta, aprovecha unos instantes de su tiempo para halagarla a ella y a su jardín. La anciana muestra, de inmediato, una súbita mejora de su estado de ánimo, puesto que su autoestima se ha visto reforzada por los piropos que Atticus, quien, buen conocedor de la gran afición de la señora Dubose por las flores, hace especial mención de ello. Su conducta es enteramente altruista y no busca con ella más que el alivio de la venerable anciana. (Goleman. 1993: 186).

\footnotetext{
13 Robert Mulligan, 1962: 0:12:28.
} 
En la próxima escena, Finch convierte una rabieta escolar de su hija Scout en la excusa perfecta para enseñarle el valor crucial de la empatía como herramienta de comprensión del prójimo. Pero no sólo eso, le muestra, además, la utilidad de llegar a acuerdos, en el terreno emocional, para la solución pacífica de los conflictos interpersonales.

4.2. Análisis de la escena en que Atticus explica a Scout en qué consiste la empatía, sin citarla como tal

(Scout está llorando en el columpio el porche):

SCOUT. (Solloza) No quiero volver...

ATTICUS. ¿Se puede saber qué demonios te pasa? Anda, cuéntamelo.

SCOUT. (Terminante) Atticus, no voy a volver a la escuela nunca más.

ATTICUS. Scout, es que hoy ha sido el primer día.

SCOUT. (Muy disgustada) No me importa. Todo me salió mal. La maestra se enfadó mucho conmigo y me dijo que tu modo de enseñarme a leer es una equivocación. Que no siguieras... Luego hizo la tontería de querer darle una moneda a Walter Cunningham, cuando todo el mundo sabe que Cunningham no quiere aceptar ningún regalo. Hasta un idiota se daría cuenta... ATTICUS. (Conciliador) Bueno, quizá estaba nerviosa. También era su primer día como maestra y, además, es nueva aquí.

SCOUT. Oh, Atticus...

ATTICUS. Anda, escúchame un momento... (Acerca a Scout a su lado y la abraza) Si consigues aprender una sola cosa te llevarás mucho mejor con todos tus semejantes. Nunca llegarás a comprender a una persona hasta que no veas las cosas desde su punto de vista.

SCOUT. ¿Cómo?

ATTICUS. Hasta que no logres meterte en su piel y sentirte... cómodamente...

SCOUT. Pero, si continúo yendo a la escuela, no podremos leer juntos.

ATTICUS. Scout, ¿sabes lo que significa «transigir»?

SCOUT. ¿No hacer caso de la ley?

ATTICUS. (Divertido) Mmm... no. Es un acuerdo al que se llega por consentimiento mutuo. Ahora te explicaré en qué consiste: tú consientes en ir a la escuela, porque es necesario, y yo consiento en que cada noche continuemos leyendo juntos, como hemos venido haciendo, ¿trato hecho? SCOUT. (Voz en off. Scout reflexiona sobre la escena vivida, en su infancia, ya siendo adulta) No había nadie capaz de explicar las cosas con tanta claridad como Atticus y, aunque, esa cualidad suya, no nos sirviera para despertar la admiración de nuestros amigos, Jem y yo teníamos que admitir que, en eso, era un maestro. Pero, nosotros, creíamos que, quizá, fuese lo único que era capaz de hacer. ${ }^{14}$

14 Robert Mulligan, 1962: 0:39:40. 
La capacidad pedagógica de Atticus es tal que su hija recuerda la escena, con infinito cariño, muchos años después, reconociendo ese extraordinario don de su padre. Es significativa, también, la ausencia de comentarios al reproche que la maestra de Scout hace a Atticus, respecto a su forma de enseñarle a leer. Simplemente cree que hace lo correcto y que tal cosa les incumbe tan sólo a su hija y a él. Y ambas cuestiones, capacidad empática y enfoque transaccional en la resolución de controversias personales, son dos valiosísimas herramientas en el ejercicio de la abogacía.

\section{El control de las relaciones (Gestión interpersonal)}

El último componente de la inteligencia emocional, según Salovey y Mayer, es la gestión interpersonal. Esto es, la capacidad de establecer relaciones con los demás y desarrollarlas. Esta cualidad está íntimamente relacionada con conceptos tales como popularidad, liderazgo y eficacia interpersonal. Como señala Goleman: «las personas que sobresalen en este tipo de habilidades suelen ser auténticas «estrellas» que tienen éxito en todas las cuestiones vinculadas a la relación interpersonal» (Goleman. 1993: 84). Veamos, seguidamente, dos ejemplos de la capacidad de relación interpersonal de Atticus Finch.

\subsection{Análisis de la escena de la visita del Señor Cunningham a Atticus}

(Por la mañana, Scout está jugando en el jardín, y llega el Sr. Cunningham, quien trae un saco de nueces para la familia):

SCOUT. Buenos días, señor Cunningham.

CUNNINGHAM. Buenos días, señorita.

SCOUT. Mi papá se está vistiendo, ¿quiere, usted, que le llame?

CUNNINGHAM. No, señorita. No quisiera molestarle.

SCOUT. No es ninguna molestia, señor Cunningham. Se alegrará de verle. (Se acerca a la puerta y llama a su padre) iAtticus, Atticus! Ha venido el señor Cunningham.

ATTICUS. (Sale a recibir al señor Cunningham) Buenos días, Walter.

CUNNINGHAM. (Algo azorado) Buenos días, señor Finch. Perdone, pero no quería molestarle. He venido a traerle estas nueces a cuenta de mi deuda. ATTICUS. Muchas gracias. La verdura que nos trajo la semana pasada era deliciosa.

CUNNINGHAM. Me alegro. Buenos días.

ATTICUS. Buenos días, Walter.

(El señor Cunningham se despide y se marcha)

ATTICUS. Scout, creo que es mejor que no me llames la próxima vez que venga el señor Cunningham.

SCOUT. ¿No te gusta darle las gracias?

ATTICUS. Claro, pero él se siente cohibido cuando se las doy. (Deja el saco de nueces en la escalera de la cocina). 
SCOUT. ¿Por qué te trae todas esas cosas?

ATTICUS. Me está pagando los honorarios de un pleito que le defendí.

SCOUT. (Intrigada) ¿Por qué te paga de esa forma?

ATTICUS. Es su único medio de poder hacerlo. No tiene dinero.

SCOUT. ¿Es pobre?

ATTICUS. Sí

SCOUT ¿Nosotros también lo somos?

ATTICUS. (Con naturalidad) Desde luego.

SCOUT. ¿Tan pobres como los Cunningham?

ATICUS. No, no tanto como eso. Ellos son campesinos y la Depresión les afectó más duramente. ${ }^{15}$

En esta escena podemos apreciar detalles muy significativos de la forma de comportarse de Atticus, con respecto al Sr. Cunningham y a su hija Scout. En primer lugar, respeta enormemente la dignidad como persona de Walter. Por eso, le dice a Scout que no le llame cuando éste venga a casa a llevar productos para saldar la deuda que tiene con él. Walter Cunningham atraviesa una situación económica difícil, pero posee un elevado concepto del honor y le avergüenza no poder compensar a Finch de otra forma que no sea en especie. Finch lo sabe y prefiere ahorrarle el mal trago de que le tenga que ver cada vez que acude a pagar. En segundo lugar, explica la situación a Scout, con la mayor naturalidad y así lo entiende ella, que pregunta a su padre acerca de su propio estatus financiero. Finch, modesto, se sitúa, a los ojos de Scout, casi en el mismo plano en su nivel de ingresos que los Cunningham, con un probable doble objeto: que Scout no valore a nadie como persona por su nivel de renta y que sea consciente de la difícil situación que experimentan muchos de sus amigos y vecinos. De nuevo, observamos el «enfoque empático» de Finch en la conversación con Scout. La conciencia de uno mismo es la facultad sobre la que se erige la empatía, puesto que, cuanto más abiertos nos hallemos a nuestras propias emociones, mayor será nuestra destreza en la comprensión de los sentimientos de los demás. (Goleman. 1993: 170). Atticus Finch se esfuerza vivamente en hacer comprender esto a su hija.

5.2. Análisis de la escena de la conversación entre Atticus y sus hijos acerca del empleo de las armas

(Atticus está sentado a la mesa con sus hijos, Scout y Jem. Los acompaña, también, Walter, compañero de clase de Scout, al que han invitado a comer. Es el hijo de Walter Cunningham, cliente y amigo de Finch.)

ATTICUS. (Dirigiéndose a Walter) Supongo que esta comida te gustará.

15 Robert Mulligan, 1962: 0:05:11. 
WALTER. Sí señor. Hace tiempo que no he comido carne asada. Sólo, de vez en cuando, podemos comer algún conejo. Mi padre y yo vamos de caza cuando no hay nada que hacer.

JEM. (Intrigado) ¿Tú tienes escopeta?

WALTER. (Sin darle importancia) Pues claro.

JEM. ¿Desde hace mucho?

WALTER. Cosa de un año o así. (Mira a Atticus) ¿Puedo tomar un poco de compota?

ATTICUS. Claro, hijo. ¿Quieres hacer el favor de traer la compota, Calpurnia?

CALPURNIA. (Desde la cocina) Sí, señor.

JEM. ¿Cuántos años tenías cuando te regalaron tu primera escopeta, Atticus?

ATTICUS. Trece o catorce. Recuerdo, muy bien, cuando mi padre me la dio. Me advirtió que no debía apuntar nunca contra nada de la casa. Y sólo me dejaba disparar, en el huerto, contra latas viejas. Pero, considerando que, tarde o temprano, me vencería, un día, la tentación de tirar a los pájaros... Dijo que ya podía matar todos los grajos que quisiera, si les daba, pero que no olvidase que matar a un ruiseñor era un grave pecado.

JEM. ¿Por qué?

ATTICUS. Pues, supongo, que porque los ruiseñores no hacen otra cosa que cantar para regalarnos el oído. No picotean los sembrados. No entran en los graneros a comerse el trigo. No hacen más que cantar con todas sus fuerzas para alegrarnos. $\rangle^{16}$

En este diálogo podemos apreciar que Finch ha sabido inculcar a sus hijos la preocupación por las necesidades de los demás: Scout y Jem han invitado a comer a Walter, su compañero de clase, porque este no se había llevado el almuerzo a la escuela, dada la precaria situación económica de su familia. Cuando surge, en la conversación, el tema de la escopeta de caza la actitud de Walter contrasta con la de Jem. Este contraste pone de manifiesto de forma evidente la diferencia de clases entre ambos. Para Walter la escopeta de caza es una herramienta de trabajo que les sirve, a su padre y a él, para paliar su deficiente alimentación abatiendo a algún conejo. Para Jem, por el contrario, la escopeta es una especie de juguete que se empeña en reclamar a su padre con un doble objeto: reivindicar que ya es mayor y poder tener una nueva distracción en la que emplear su tiempo libre. No obstante, la parte esencial de la conversación es la declaración de principios de Atticus respecto al uso de las armas. Señalar que, más allá de su literalidad, encarna un elevado valor simbólico, reflejado en la figura del «ruiseñor». No sólo previene a Jem de la necesaria capacidad de discernimiento a la hora de abatir una pieza $u$ otra cuando dispare su arma. Le indica que no todo está permitido. Y lo hace transmitiendo las enseñanzas que,

\footnotetext{
${ }^{16}$ Robert Mulligan, 1962: 0:36:09.
} 
en su día, le inculcó su propio padre (el abuelo de Jem). La carga icónica de la imagen del pájaro, y la enseñanza que lleva aparejada, sirven para dar título a la película. La escena refleja, también, el fuerte ascendiente de Atticus sobre sus hijos, a los que siempre trata con respeto y a los que deja expresar sus opiniones, aun siendo consciente de que son niños. En este caso las relaciones interpersonales del protagonista se desenvuelven en el ámbito estrictamente familiar, pero ello no es óbice para que, una vez más, podamos concluir que la inteligencia emocional del personaje nos parece sobresaliente.

\section{EL ESTILO DE LIDERAZGO DE ATTICUS FINCH Y SU TRASCENDENCIA EN LA DEFENSA DE TOM ROBINSON}

Tras analizar la inteligencia emocional de nuestro protagonista, Atticus Finch, dedicaremos el presente epígrafe al estudio de su capacidad y estilo de liderazgo. Incidiremos también en la trascendencia práctica de tales cuestiones en la defensa de su cliente, Tom Robinson.

\section{1. ¿Qué es el liderazgo? Liderazgo e inteligencia emocional.}

Existen numerosas definiciones de liderazgo, en la literatura de la gestión de empresas. De entre todas ellas, nos parece sumamente certera la del consultor Stephen R. Covey:

«El liderazgo en realidad es el arte de posibilitar. El propósito de las escuelas es educar a los niños, pero si uno tiene un mal liderazgo, uno tiene una mala educación. El propósito de la medicina es ayudar a la gente a ponerse bien, pero si uno tiene un mal liderazgo, uno tiene una mala medicina. Un ejemplo tras otro, podrían demostrar que el liderazgo es la más elevada de las artes, simplemente porque posibilita que todas las otras artes y profesiones funcionen (...) El liderazgo en la Era de los Trabajadores del Conocimiento se caracterizará por aquellos que encuentren su propia voz y que, cualquiera que sea su posición, inspiren a otros a encontrar la suya. Será un liderazgo en el que la gente comunique con tanta claridad a los demás el valor y el potencial que tienen, que ellos podrán verlo por sí mismos. En eso radica un futuro ilimitado»». ${ }^{17}$ (Covey. 2010: 23-31).

Así pues, Covey nos habla, en su bella aproximación conceptual, de liderazgo como «arte de posibilitar» pero ¿cómo se consigue tal cosa? Goleman, Boyatzis y McKee nos dan algunas pistas para ello:

«El líder es la persona que mejor sabe encauzar las emociones del grupo (...) Cuando los líderes encauzan las emociones en una dirección positiva

${ }^{17}$ Stephen R. Covey, 2010: 23-31. 
movilizan lo mejor de las personas y provocan un efecto al que llamamos «resonancia»(...) Por todo eso la clave del liderazgo primal (como acto original y como el acto más importante del liderazgo) se asienta en las competencias de la inteligencia emocional que posean los líderes, es decir, en el modo en que gestionan la relación consigo mismos y con los demás.» (Goleman, Boyatzis y McKee. 2002: 33-34).

El liderazgo, entonces, y completando entre sí, ambas definiciones, sería: «el arte de posibilitar, a través de la gestión positiva de las emociones, propias y del entorno, el máximo grado de desarrollo del potencial de las personas (resonancia), para alcanzar las metas más elevadas que puedan plantearse a cualquier organización humana, en el presente o en el futuro». Vemos, por tanto, que el liderazgo y la inteligencia emocional están íntima, e intrínsecamente, unidos.

\section{Los estilos de liderazgo. El liderazgo transformacional.}

Casi tan numerosas, como las definiciones de liderazgo, son las taxonomías de los diversos estilos de liderazgo. Centrándonos en las especiales características del personaje de Atticus Finch hemos optado por clasificar su liderazgo como «transformacional» (de acuerdo con los criterios de Bass y Avolio, 1997). Así explican el concepto los profesores Molero y Cuadrado, especialistas en psicología de las organizaciones: «Según Bass (1985) hay dos tipos de liderazgo, uno de «bajo nivel», basado en el intercambio de recompensas entre líder y seguidores al que denomina liderazgo transaccional. El liderazgo transaccional, cuando se aplica adecuadamente, produce efectos positivos en los subordinados y en la organización, pero dichos efectos tienen un carácter limitado. El líder transformacional, por su parte, es capaz de cambiar los valores, creencias y actitudes de las personas que trabajan con él, aumentando la eficacia de su unidad de trabajo más allá de lo esperado. Este tipo de liderazgo puede darse, en mayor o menor grado, en cualquier tipo de organización y en cualquier nivel de ella. (...) Son este tipo de líderes los que, bajo las circunstancias adecuadas, crean y transforman las culturas organizacionales $\rangle^{18}$. El líder transformacional se caracteriza por las siguientes cualidades (Bass y Avolio, 1997, citados por Molero y Cuadrado, 2004):

a) Influencia idealizada-carisma (aspectos atribucionales). Este factor señala los aspectos de la conducta del líder que contribuyen a que se le atribuya carisma por parte de las personas que trabajan con él. Entre los ítems que constituyen este factor podemos mencionar, por ejemplo «Me

${ }_{18}$ Fernando Molero, Isabel Cuadrado, 2004: 203-204. 
hace sentir orgulloso de trabajar con él». La reacción de Jem, tras el abatimiento del perro rabioso por Atticus, refleja válidamente este ítem.

b) Influencia idealizada-carisma (aspectos conductuales). Parecido al anterior. Este factor se centra, sin embargo, en las posibles conductas de los líderes carismáticos, como la que se expresa a través del ítem «Nos habla de los valores y creencias importantes para él». Apreciamos este ítem en el diálogo que Atticus mantiene, con sus hijos, acerca del uso de las armas de fuego, transmitiéndoles sus valores y creencias sobre ello.

c) Motivación inspiracional. Este factor puede solaparse en ocasiones con los dos anteriores dependiendo de hasta qué punto las personas asociadas con el líder busquen identificarse con él. Sin embargo, la motivación inspiracional hace referencia al grado en que el líder es capaz de transmitir la importancia de la misión a realizar. Un ítem ejemplo de este factor es «Articula una atractiva visión de futuro». La explicación de Atticus a Scout del motivo por el que defiende a Tom Robinson, y la trascendencia que ello implica para las generaciones venideras, representadas por Scout y Jem, constituye un muy buen ejemplo de este ítem.

d) Estimulación intelectual. Hace referencia a aquellas conductas del líder que motivan a las personas que trabajan con él a pensar por sí mismos y a resolver los problemas de forma creativa. Un ítem ejemplo de este factor es «Hace que vea los problemas desde ángulos diferentes». La escena de la conversación entre Atticus y Scout, tras su primer día de escuela, encajaría a la perfección en este ítem.

e) Consideración individualizada. Las conductas expresadas en este factor señalan a un líder que trata a las personas que trabajan con él de manera individual y les proporciona consejo cuando es necesario. El ítem «Me trata más como persona individual que como miembro de un grupo» es uno de los que constituyen este factor. La forma en que Atticus se preocupa en tener al corriente a Helen, a la esposa de Tom Robinson, de las vicisitudes procesales de su marido, más allá de una típica, y fría relación abogado-cliente es un adecuado reflejo de este ítem.

Una vez descritas las características del liderazgo transformacional, sus ítems y su correspondencia con las escenas analizadas de la película, podemos concluir que Atticus Finch es, en nuestra opinión, un líder transformacional. Dicho de otro modo, por Goleman, Boyatzis y McKee:

«Los líderes que poseen una elevada conciencia emocional están en contacto con sus señales interiores y reconocen el modo en que sus sentimientos les afectan y acaban influyendo en su rendimiento laboral. Son personas que también están en contacto con los valores que les guían y que, muy a menudo, 
pueden ver la imagen global de una determinada situación compleja e intuir así el curso de acción más adecuado. Los líderes emocionalmente conscientes de sí mismos suelen ser sinceros y auténticos y son capaces de hablar abiertamente de sus emociones y de expresar con convicción la visión que les guía.» (Goleman, Boyatzis y McKee. 2002: 309).

A mayor abundamiento, el consultor Chris Lowney afirma:

«Los líderes verdaderos, los verdaderos héroes, encuentran realización, significado y hasta éxito al tender la mirada más allá de su propio interés para servir al prójimo, y se crecen si enfocan algo más grande que el solo interés propio». ${ }^{19}$ (Lowney. 2008: 298).

Veamos, seguidamente, como trasciende ese liderazgo en la defensa de Tom Robinson.

\section{El estilo de liderazgo de Atticus Finch y su trascendencia en la defensa de Tom Robinson: empatía, autoconocimiento, autogestión, gestión interpersonal y motivación}

Finch desarrolla, como abogado, una estrategia de defensa proactiva. Su principal línea argumental se centra en desmontar las falacias del relato de la acusación. Y lo hace de una manera extraordinariamente sencilla: poniendo el foco en los hechos objetivamente demostrables y rebatiendo las conjeturas de los demandantes perjuros, a quienes consigue dejar en evidencia frente al jurado.

La sencillez del discurso de Finch viene dada porque lo adapta a su auditorio y al jurado: gente del medio rural, con un nivel de instrucción formal bajo y escasos conocimientos jurídicos, pero perfectamente capaces de discernir lo que ha pasado y las diferencias entre el bien y el mal. Esto, en sí mismo, no es más que una aplicación práctica de la empatía y la gestión interpersonal.

Veamos, pues, los principales puntos de la defensa de Tom Robinson:

- El día de autos, no hubo constatación médica de que el delito denunciado se hubiese producido realmente. Esto, constituye una gravísima falta de diligencia, por parte del sheriff Tate, y debería haber provocado el archivo de la causa, en ausencia de otras pruebas concluyentes, como señala Finch en su alegato final.

- La víctima fue agredida (esto es lo único que parece claro y verdadero en todo el caso) por un hombre zurdo, pero el acusado perdió toda la movilidad de su brazo izquierdo, tras un accidente laboral, cuando era un niño. Por tanto, resulta de todo punto imposible el que pudiese haber agredido a la denunciante de la forma que ella relata.

${ }^{19}$ Chris Lowney, 2008: 298. 
- La única testigo de los hechos es la propia víctima y su testimonio y el del acusado son diametralmente opuestos. El padre de la víctima sólo puede acreditar que el procesado estaba en el lugar donde ocurrieron los hechos cuando él llegó. Nada más.

- En un brillante interrogatorio, y mostrando un gran respeto por la teórica víctima, Mayella Ewell, Finch logra desmontar su relato, por inconsistente, y viene a demostrar que sólo pudo haber sido golpeada por su propio padre (alcohólico, violento y maltratador), al que también interroga y del que queda constancia, tras pedirle Atticus que escriba su nombre en un papel, que es zurdo.

- No obstante, todo ese esfuerzo de oratoria y argumentación jurídica no vale absolutamente para nada. Tom Robinson es condenado por un jurado que se deja arrastrar por sus perjuicios y cuyo veredicto parece haber estado predeterminado de antemano. Ello no es motivo para que su abogado desfallezca. En este sentido, señala el profesor Rodríguez Mourullo: «Como se ve, cuando nos adentramos en un proceso judicial, no nos hallamos en el mundo de las premisas incontestables que, a través de una demostración analítica, conducen a una conclusión necesaria, sino en el reino de lo opinable, de lo discutible, en el marco de lo dual, de las dos verdades, la duda y el duelo dialéctico que abre paso a la decisión final, es decir, a la elección de una entre las varias soluciones posibles, porque la sentencia no encierra nunca la justicia absoluta, sino - como con acierto subrayó Legaz y Lacambra- «un punto de vista sobre la justicia». ${ }^{20}$ (Rodriguez Mourullo. 1988: 23-24).

- Y ese «punto de vista sobre la justicia», expresado por el jurado, y, a la sazón, bastante «injusto», lejos de desmoralizarle a Finch, le impele a perseverar. Confía en poder lograr la absolución de su cliente en la segunda instancia y, en cuanto concluye el juicio, comienza a pensar en la apelación (denotando un elevado grado de autoconocimiento, autogestión y motivación). La trágica muerte de Tom Robinson cercena toda posibilidad de seguir luchando por su inocencia.

En resumen, el letrado Finch despliega todo su abanico de herramientas jurídicas y de liderazgo e inteligencia emocional en el proceso, pero no puede evitar que su cliente sea condenado por una triste y terrible razón: Tom Robinson es declarado culpable, únicamente, por ser afroamericano. Es el color de su piel, y no sus actos, lo que le lleva a la cárcel. Lo condenan los prejuicios, no los argumentos jurídicos, y en esa tesitura no hay ley ni abogado capaces de hacer triunfar la verdad.

${ }^{20}$ Gonzalo Rodríguez Mourullo, 1988: 23-24. 


\section{VALORACIÓN CRÍTICA DE LA PELÍCULA. CONCLUSIONES}

- El filme, basado en la novela homónima de la escritora Harper Lee, constituye una crítica a la segregación y a la discriminación raciales. El personaje del abogado Atticus Finch es presentado como un modelo de comportamiento ético a seguir, en un momento histórico, los años sesenta, en que las tensiones raciales pasaron a articularse socialmente a través del movimiento por los derechos civiles; estableciéndose así un cauce de lucha política frente a una situación de violencia generalizada contra la población afroamericana. Así lo expresa Howard Zinn, historiador progresista estadounidense:

«En 1967 tuvieron lugar los mayores disturbios urbanos de la historia americana en los «ghettos» negros del país. Según el informe del Comité de Consejo Nacional para los Disturbios Urbanos, hubo ocho alzamientos importantes, treinta y tres sublevaciones "graves, pero no trascendentes» y ciento veintitrés «pequeños» disturbios. Murieron ochenta y tres personas por disparos de armas de fuego, en su mayoría en Newark y Detroit. «La abrumadora mayoría de personas que murieron o resultaron heridas en todos los disturbios eran civiles negros». El «alborotador típico» -según la Comisión- era el joven que había dejado el instituto de educación secundaria, pero «con una educación ligeramente más alta que su vecino negro no alborotador» y «la mayoría de las veces con trabajos parciales o de baja categoría»; estaba «orgulloso de su raza, y era extremadamente hostil tanto hacia los blancos como hacia los negros de clase media, y aunque estaba al corriente de la situación política, no tenía ninguna confianza en el sistema político» ${ }^{21}$. (Zinn. 2005: 426-427). El hecho de que gran parte de estas situaciones perduren en nuestros días debería hacernos reflexionar, entre otras cosas, acerca de la falta de liderazgo e inteligencia emocional entre la clase política. No es menos preocupante el escaso ejercicio del criterio por parte de los ciudadanos a la hora de dar su apoyo en las urnas a determinadas fuerzas políticas que hacen de ideas simples, verdades a medias, o completas mentiras la esencia de sus idearios y programas. El «alborotador típico», al que aludía Zinn, se ha convertido, hoy, en votante y apoyo de lo que se ha dado en llamar «populismo» pero que, en realidad, no es más que una manifestación contemporánea de la demagogia más añeja.

- En la película son patentes, también, otro tipo de críticas no tan incisivas. Entre ellas, al sistema del jurado, del que Finch expresa sus dudas, pero sin llegar a profundizar e identificarlo como un medio de control social de ciertos grupos mediante la selección sesgada y arbitraria de sus componentes (todos hombres de raza blanca). Finch cree en el sistema, más allá de los fallos de éste. Se focaliza la atención en el caso

${ }^{21}$ Howard Zinn, 2005: 426-427. 
concreto de Tom Robinson, pero la crítica al racismo y a la segregación racial no ahonda en las raíces últimas de la misma. Lo mismo ocurre con la identificación entre criminalidad e ignorancia, pobreza, alcoholismo y baja extracción social. Los delincuentes son los desfavorecidos. Para los sociólogos criminales Reiman y Leighton:

«Parece extenderse la idea de que el objetivo de nuestro sistema jurídico penal no es eliminar el delito o llegar a alcanzar la justicia sino proyectar, a la ciudadanía estadounidense, una imagen creíble de la amenaza del crimen como una amenaza proveniente de los pobres. Para completar esta visión, la administración de justicia exhibe ante nuestros ojos una considerable nómina de delincuentes pobres.» ${ }^{22}$ (Reiman y Leighton. 2013: 1).

- Dada que la acción de la obra se sitúa en 1932, incluso el propio Atticus Finch entiende como tolerables ciertos niveles de racismo. Nos referimos a la conveniencia de que no se establezcan relaciones personales mixtas entre blancos y afroamericanos. Y lo expresa, en su propio alegato, ante el jurado:

ATTICUS. (...) ¿Y qué era lo que había hecho (Mayella Ewell)? Había tentado a un negro. Ella era blanca y había tentado a un negro. Hizo una cosa que en nuestra sociedad es algo imperdonable: besar a un hombre negro. ${ }^{23}$

- Y es que existe un elevado grado de machismo subyacente en la película. Podría establecerse una suerte de paralelismo simbólico entre el personaje de Mayella Ewell y la Eva bíblica. Ambas son las que traen el mal al «Paraíso»: tientan al hombre y le conducen a su perdición. Salvo Mayella, y con la excepción del personaje de Scout, (independiente, rebelde y soñadora, aunque se nos presente un tanto «asilvestrada», en su aspecto físico y atuendo, como queriendo recalcar su orfandad y la ausencia de un referente materno) cuyo protagonismo se refuerza por ser la narradora de los hechos, los personajes femeninos tienen un papel marcadamente secundario: la señorita Maudie, la tía Stephanie, la señora Dubose y la asistenta, Calpurnia son más observadoras de lo que ocurre que motores de la acción.

- El personaje de Boo Radley presenta un marcado carácter ambivalente. Se trata de un joven discapacitado, al que su familia oculta por vergüenza, y al que todos temen, por desconocimiento e ignorancia, pero que acaba salvando de la muerte a Scout y Jem. La interpretación de las implicaciones subconscientes que encarna el personaje no es sencilla.

22 Jeffrey Reiman, Paul Leighton, 2013: 1.

${ }^{23}$ Robert Mulligan, 1962: 1:31:14. 
Por un lado, podríamos extraer la conclusión de que muchas veces somos injustos en nuestras apreciaciones respecto a los demás y que aquellos que catalogamos como potencialmente peligrosos para nosotros son, en realidad, aquellos con los que tenemos más en común y quienes pueden salvarnos/comprendernos. Por otro, Boo Radley encarnaría una suerte de invocación subliminal a la justicia primitiva, más allá de un sistema jurídico penal inhumano e injusto que deja libre al culpable y lleva a la muerte al inocente.

- Pensamos que el personaje de Atticus Finch, con ligeros ajustes y matices, y su fuerte compromiso ético, no ha perdido vigencia con los años. Pero hoy, nuestro abogado, tendría que lidiar con una nueva y compleja realidad, incipiente en los años treinta del siglo XX, pero omnipresente en nuestros días: los medios de comunicación de masas y su doble función; como agentes amplificadores de la realidad, y como medio de control social. El caso de Tom Robinson sería, muy posiblemente, retransmitido en directo por la Fox, la CNN, la ABC y la CBS y acapararía las portadas del USA Today y del New York Post, a la par que suscitaría hondos debates en los sesudos Washington Post y New York Times. El sociólogo del derecho Herbert J. Gans clasifica las noticias que se difunden en los medios en dos tipos:

«Un primer tipo sería el denominado «noticias del desorden», que nos informarían tanto de las amenazas a varios tipos de orden como de las medidas tomadas para restaurarlo. El segundo tipo, que llamaríamos «noticias cotidianas», incluiría una selección de noticias «oficiales», debidamente elegidas y aprobadas por el poder. Ambos tipos de noticias, a pesar de sus diferencias, ayudan a reproducir el orden social dominante». ${ }^{24}$ (Gans. 1980: 52).

El caso de Tom Robinson podría ser objeto de difusión mediática encuadrado en cualquiera de las dos clases. En el primer supuesto, exacerbando el carácter supuestamente sexual de la agresión y poniendo el foco en que el presunto agresor es un afroamericano. En el segundo, desde una perspectiva pretendidamente más «neutra», dando cuenta del suceso y haciendo énfasis en la pronta respuesta de las autoridades para la detención, y puesta a disposición del jurado, del presunto agresor.

En síntesis, y a modo de colofón, señalar que, en nuestra opinión, Atticus Finch encarna un modelo sobresaliente de inteligencia emocional y liderazgo aplicado a la profesión jurídica. El hecho de que se trate de un personaje de ficción no le resta un ápice de interés a su figura y esperamos haber contribuido, con nuestro análisis crítico, a reivindicar la importancia que tiene la

${ }^{24}$ Herbert J. Gans, 1980: 52. 
defensa letrada para el buen funcionamiento del sistema jurídico penal y, en suma, de la sociedad en su conjunto.

\section{BIBLIOGRAFÍA}

ANÓNIMO, VARIOS AUTORES, (2002): Reglas para formar un abogado (Edición facsímil de la original de 1794). Maxtor, Valladolid.

Aquino, Tomás De, (2014): Suma de Teología. Biblioteca de Autores Cristianos, Madrid.

Cicerón, Marco Tulio, (1998): Los oficios o los deberes. Edición de Joaquín Peñalosa, Porrúa, Méjico D.F.

Covey, Stephen, (2010) El liderazgo es un arte que posibilita. En Frances Hesselbein y Alan Shrader, (2010): De líder a líder, Granica, Buenos Aires.

Fооте, Horton, (1962): To kill a Mockinbird (Final Screenplay). Universal Studios, Hollywood.

Gans, Herbert, (1980): Deciding What's News: A Study of CBS Evening News, NBC Nightly News, Newsweek and Time. Vintage Books. Nueva York.

GARDNER, Howard, (1983): Frames of Mind. The Theory of Multiple Intelligences. Basic Books, Nueva York.

Goleman, Daniel, (1996): Inteligencia emocional. Kairós, Barcelona.

Goleman, Daniel; Boyatzis, Richard y McKeE, Annie, (2002): El líder resonante crea más. Plaza y Janés, Barcelona.

Lowney, Chris, (2008): El liderazgo al estilo de los jesuitas, Edigrabel, Barcelona.

Molero, Fernando; CuADRADO, Isabel, (2004) El liderazgo y la cultura en las organizaciones. En Amparo Osca, (2004): Psicología de las organizaciones, Sanz y Torres, Madrid.

Mulligan, Robert, (1962): Matar a un ruiseñor. Universal Studios, Hollywood.

Pérez, Matilde, (2017): «La epiqueya en la visión de Francisco Suárez», Prudentia Iuris, núm. 83.

Powell, Colin, (2012): It Worked for me. Harper Collins, Nueva York.

RAFTER, Nicole, (2006): Shots in the Mirror. Oxford University Press, Nueva York.

Raiman, Jeffrey; Leighton, Paul, (2013): The Rich get Richer and The Poor get Prison. Pearson, Nueva Jersey.

RodríGuez Mourullo, Gonzalo,(1988): Aplicación judicial del derecho y lógica de la argumentación jurídica. Cívitas, Madrid.

SALOVEY, Peter; MAYER, John, (1990): «Emotional Intelligence», Imagination, Cognition and Personality, vol. 9, núm. 3.

SHIELDS, Charles J., (2006): Mockingbird, a Portrait of Harper Lee. Henry Holt and Company, Nueva York.

ZINN, Howard, La otra historia de Estados Unidos (2005), Hiru, Hondarribia. 


\title{
ATTICUS FINCH: INTELIGENCIA EMOCIONAL Y LIDERAZGO, COMO HERRAMIENTAS DE GESTIÓN, EN EL EJERCICIO DE LA ABOGACÍA. (ANÁLISIS DE LA PELÍCULA «MATAR A UN RUISEÑOR»)
}

\author{
Atticus Finch: Emotional Intelligence and Leadership, as
} Management Tools, in the Exercise of the Legal Profession. (Analysis of the film "To kill a Mockingbird")

\author{
Manuel-Óscar Remeseiro Fernández \\ Doctorando en Derecho y Ciencias Sociales \\ Universidad Nacional de Educación a Distancia (U.N.E.D.)
}

http://dx.doi.org/10.18543/ed-67(2)-2019pp321-351

\section{Copyright}

Estudios de Deusto es una revista de acceso abierto, lo que significa que es de libre acceso en su in tegridad. Se permite su lectura, la búsqueda, descarga, distribución y reutilización legal en cualquier tipo de soporte sólo para fines no comerciales, sin la previa autorización del editor o el autor, siempre que la obra original sea debidamente citada y cualquier cambio en el original esté claramente indicado

Estudios de Deusto is an Open Access journal which means that it is free for full access, reading, search, download, distribution, and lawful reuse in any medium only for non-commercial purposes, without prior permission from the Publisher or the author; provided the original work is properly cited and any changes to the original are clearly indicated. 